\title{
Perencanaan Peron Stasiun Tarik Pada Proyek Pembangunan Jalur Ganda Lintas Sepanjang Mojokerto
}

\author{
Nico Djajasinga ${ }^{1 *}$, Annasthasya Noor Asyifa ${ }^{2}$, Siti Umiyati ${ }^{3}$ \\ 1), 2), 3)PTDI-STTD \\ *Email : nico.djajasinga@ptdisttd.ac.id
}

\begin{abstract}
This research to find out the platform planning in Tarik Station for development project double track Sepanjang Mojokerto. Because old platforms in Tarik Station has some equipment flaws and requires planning in regulating the movement of passenger flows. So, writer resarched platform planning adjusted to platform technical requirements contained in PM 29 tahun 2011 and placement of platform tailored to Detail Engineering Desain (DED). This is to correct deficiencies in the existing and planning platforms in the context of double track development. This research method uses analysis existing platform condition and Level of Sevice, forecasting method total passengers for the next years by arithmetic and passenger movement flow for Detail Engineering Desain (DED) building layout station. Results of analysis and research it is known that suitable width of platform Tarik Stations for double track are 2 meters for side platform and 4 meters for island platform. While the length of the platform is 140.7 meters. The flow of passenger movement is facilitated by an exit that is different from the entrance. So that there is a separation of the flow of passengers who will go to the platform and passengers who will leave the station.
\end{abstract}

Keywords: Planning, Platform, forecasting, Level of Service.

\begin{abstract}
Abstrak
Penelitian ini untuk mengetahui perencanaan platform di Stasiun Tarik untuk proyek pembangunan double track Sepanjang Mojokerto. Karena peron lama di Stasiun Tarik memiliki beberapa kekurangan peralatan dan memerlukan perencanaan dalam mengatur pergerakan arus penumpang. Maka penulis melakukan penelitian perencanaan platform yang disesuaikan dengan persyaratan teknis platform yang tertuang dalam PM 29 tahun 2011 dan penempatan platform disesuaikan dengan Detail Engineering Desain (DED). Hal ini untuk memperbaiki kekurangan pada platform yang ada dan platform perencanaan dalam konteks pembangunan jalur ganda. Metode penelitian ini menggunakan analisis kondisi peron eksisting dan Level of Service, metode peramalan jumlah penumpang tahun depan secara aritmatika dan arus pergerakan penumpang untuk Detail Engineering Desain (DED) building layout station. Hasil analisa dan penelitian diketahui bahwa lebar peron yang sesuai Stasiun Tarik untuk double track adalah 2 meter untuk peron samping dan 4 meter untuk peron pulau. Sedangkan panjang platform adalah 140,7 meter. Arus pergerakan penumpang difasilitasi oleh pintu keluar yang berbeda dengan pintu masuk. Sehingga ada pemisahan arus penumpang yang akan menuju peron dan penumpang yang akan keluar stasiun.
\end{abstract}

Kata kunci: Perencanaan, Platform, Peramalan, Tingkat Pelayanan.

\section{A. PENDAHULUAN}

Transportasi sebagai salah satu pendorong pembangunan yang penting dalam membangun perekonomian suatu negara. Bersama dengan perkembangan itu, manusia sebagai pelaku utama dan barang sebagai objek utama dalam perkembangan itu membutuhkan moda yang dapat mendukung perpindahan manusia dan barang. Kereta api merupakan salah satu moda transportasi nasional yang mempunyai karakteristik pengangkutan secara massal dan keunggulan tersendiri, yang tidak dapat dipisahkan dari moda transportasi lain, perlu dikembangkan potensinya dan ditingkatkan peranannya sebagai penghubung wilayah, baik nasional maupun internasional, untuk menunjang, mendorong, dan menggerakkan pembangunan nasional guna meningkatkan kesejahteraan rakyat.

Menurut Undang-Undang Nomor 23 Tahun 2007 tentang Perkeretaapian menyatakan bahwa "Perkeretaapian adalah satu kesatuan sistem yang terdiri atas prasarana, sarana, dan sumber daya 
manusia, serta norma, kriteria, persyaratan, dan prosedur untuk penyelenggaraan transportasi kereta api”. Untuk meningkatkan peran angkutan perkeretaapian memerlukan prasarana yang menunjeng penyelenggaraan operasinya. Yang dimaksud prasarana perkeretaapian yaitu jalur kereta api, stasiun kereta api, dan fasilitas operasi kereta api agar kereta api dapat dioperasikan (Undang-Undang Nomor 23 tahun 2007 Pasal 1 ayat 3).

Di pulau Jawa, saat ini sistem perkeretaapian dapat dikatakan sudah baik. Karena kebutuhan pergerakan penumpang dan barang yang terus meningkat, maka dibutuhkan usaha untuk memfasilitasinya. Hal tersebut dapat dilakukan dengan banyak cara, salah satunya adalah dengan membuat jalur ganda (double track).

Menurut Peraturan Presiden Nomor 109 tahun 2020 salah satu Proyek Strategis Nasional yaitu membangun double trackjawa selatan. Balai Teknik Perkeretaapian Kelas I Wilayah Jawa Bagian Timur mewujudkannya dalam 2 bentuk Rencana Strategis. Salah satu Rencana Strategis Balai Teknik Perkeretaapian Kelas I Wilayah Jawa Bagian Timur tahun 2020-2024 yaitu meningkatnya kapasitas prasarana transportasi kereta api diwilayah Balai Teknik Perkeretaapian Wilayah Jawa Bagian Timur. Dengan Indikator Kinerja Kegiatan (IKK) yaitu pembangunan jalur kereta api baru termasuk jalur ganda dan reaktivasi yang selesai. Salah satunya yaitu pembangunan jalur ganda Sepanjang Mojokerto.

Saat ini proses pembangunan jalur ganda pada KM 23+000 sampai dengan KM 56+000 lintas Sepanjang - Mojokerto dengan panjang lintas sekitar $33 \mathrm{~km}$. Pada proyek pembangunan jalur ganda lintas SepanjangMojokerto melewati beberapa stasiun salah satunya stasiun Tarik. Berdasarkan buku Peraturan Stasiun (PD. 22 Jilid I Pasal 3 ayat 1) Stasiun Tarik (TRK) merupakan stasiun kereta api yang terletak di Tarik, Sidoarjo. Stasiun yang terletak di ketinggian $+16 \mathrm{~m}$ ini berada di Daerah Operasi VIII Surabaya dan berlokasi paling barat di Kabupaten Sidoarjo. Stasiun ini memiliki 5 jalur dengan, jalur 2 digunakan sebagai sepur lurus, jalur 1 dan jalur 3 menjadi jalur persilangan, dan jalur 4 merupakan jalur menuju Sidoarjo. Sedangkan jalur 5 dijadikan jalur darurat.

Akibat perubahan dari jalur tunggal menjadi jalur ganda menyebabkan perubahan pada layout emplasemen stasiun Tarik. Perubahan tersebut menyebabkan perubahan pada perencanaan peron. Peron stasiun kereta dibuat berdasarkan perencanaan yang telah dikaji, tidak semua peron memiliki ukuran dan luas yang sama, tergantung dari jenis stasiun, operasi kereta dan kapasitas penumpang harian. Berdasarkan survey yang telah dilakukan dan sesuai Permenhub Nomor 29 Tahun 2011 tentang Persyaratan Tehnis Bangunan Stasiun Kereta Api menyatakan bahwa panjang peron sesuai dengan rangkaian terpanjang kereta penumpang yang beroperasi dan lebar peron berdasarkan jumlah penumpang. Perencanaan peron ini dilakukan untuk mengetahui arus pergerakan penumpang dan kapasitas penumpang harian yang dapat ditampung oleh peron.

Melalui penjelasan di atas, maka peneliti berencana untuk meneliti mengenai perencanaan peron stasiun Tarik pada pembangunan proyek jalur ganda lintas Sepanjang-Mojokerto.

\section{B. KAJIAN LITERATUR Perencanaan}

Perencanaan merupakan beberapa aktivitas atau pekerjaan yang digunakan sebagai acuan untuk membuat suatu keputusan. Proses perencanaan merupakan hal yang sangat penting untuk merealisasikan tujuan yang telah di tetapkan supaya dapat terlaksana sesuai dengan keinginan. Menurut Undang-Undang Nomor 25 Tahun 2004 tentang Sistem Perencanaan Pembangunan Nasional, "perencanaan didefinisikan sebagai suatu proses untuk mentukan tindakan masa depan yan tepat, melalui urutan pilihan, dengan memperhitungkan sumber daya yang tersedia". Sedangkan menurut para ahli definisi Perencanaan adalah, antara lain:

a) Erly Suandy dalam Taufiqqurokhman (2008:4) Secara umum perencanaan merupakan proses penentuan tujuan organisasi (perusahaan) dan kemudian menyajikan (mengartikulasikan) dengan jelas strategi-strategi (program), taktik-taktik (tata cara pelaksanaan program) dan operasi (tindakan) yang diperlukan untuk mencapai tujuan perusahaan secara menyeluruh. 
b) Alder dalam Taufiqqurokhman (2008:3) Perencanaan adalah suatu proses menentukan apa yang ingin dicapai pada masa yang akan datang serta menetapkan tahapan-tahapan yang dibutuhkan untuk mencapainya.

Dari uraian diatas dapat disimpulkan bahwa perencanaan merupakan suatu proses untuk menentukan tujuan dan tindakan yang akan dicapai melalui tata cara pelaksanaan yang memperhitungkan sumber daya yang tersedia.

\section{Stasiun}

Stasiun yang kita ketahui merupakan tempat berhenti dan berangkat kereta api. Menurut Peraturan Menteri Perhubungan Nomor 29 Tahun 2011 tentang Persyaratan Teknis Bangunan Stasiun Kereta pengertian stasiun yaitu "stasiun kereta api merupakan prasarana kereta api sebagai tempat pemberangkatan dan pemberhentian kereta api".

Secara sempit stasiun dapat diartikan sebagai tempat pemberhentian kereta api untuk memberi kesempatan pada penumpang membeli karcis dan naik maupun turun dari kereta api disamping itu juga memberi fasilitas bagi penumpang untuk mengirim atau menerima barang dengan kapasitas tertentu tergantung jenis kereta api yang melewatinya dan jenis stasiun yang tersedia. Sedangkan menurut para ahli definisi stasiun adalah sebagai berikut:

a) Menurut J. Honing (1981) dalam Maulana (2019) Stasiun adalah kumpulan jalan kereta api (rel), emplasemen, gedung, dan perlengkapan lainnya yang merupakan satu kesatuan dan diperlukan dalam melakukan dinas perjalanan kereta api.

b) Menurut Warpani (1990) dalam Rizki, Sasmito, and Maria (2015) Stasiun adalah tempat berkumpulnya penumpang dan barang yang menggunakan moda angkutan kereta api. Selain itu, stasiun berfungsi sebagai tempat pengendali dan pengatur lalu lintas kereta api, sebagai depo kereta api. Stasiu besar sering pula sebagai tempat perawatan kereta api dan lokomotif. Stasiun adalah terminal akhir dan awal perjalanan kereta api namun bukan merupakan tujuan atau awal perjalanan sebenarnya.

c) Menurut Nurdiansyah and Sudarwati (2020) Stasiun Kereta Api merupakan prasarana kereta api sebagai tempat pemberangkatan dan pemberhentian kereta api. Stasiun kereta api terdiri beberapa jenis sesuai dengan fungsinya antara lain Stasiun Penumpang, Stasiun Barang dan Stasiun Operasi. Stasiun penumpang merupakan stasiun untuk keperluan naik turun penumpang. Stasiun barang merupakan stasiun kereta api untuk keperluan bongkar muat. Stasiun Operasi merupakan stasiun kereta api untuk menunjang pengoperasian kereta api. Stasiun kereta api terdiri atas emplasemen stasiun dan bangunan stasiun. Emplasemen terdiri dari atas jalan rel, fasilitas pengoperasian kereta api dan drainase.

Sedangkan secara luas stasiun dapat diartikan sebagai pusat perpindahan manusia (pengumpulan dan pendistribusian) sehingga menjadi pusat pertemuan beberapa macam alat transportasi serta aktivitas komersial yang relevan.

\section{Peron}

Hampir semua stasiun memiliki peron, umumnya stasiun besar memiliki banyak peron. Peron berasal dari bahasa Belanda yang artinya adalah jalan kecil yang sejajar dengan rel kereta api tempat lalu Lalang penumpang di stasiun kereta api, halte kereta api, atau tempat pemberhentian transportasi rel lainnya. Menurut Kamus Besar Bahasa Indonesia (KBBI) peron diartikan sebagai pelataran (halaman) pada stasiun kereta api, tempat penumpang menunggu atau tempat turun naik kereta;bus pelataran pada stasiun bus, tempat penumpang menunggu dan turun naik bus. berikut:

Sedangkan menurut para ahli pengertian peron adalah sebagai

a) Menurut Railway group Standart (1995) yang terdapat pada (Syamsudin 2011) peron adalah lantai pelataran tempat naik-turun para penumpang kereta api dan merupakan jalur rel melintas kereta api di stasiun. 
b) Menurut Railway group Standart (2000) yang terdapat pada (Khamdevi 2015) Peron adalah bagian dari stasiun yang menyediakan akses ke atau dari kereta api.

c) Menurut (Nurdiansyah and Sudarwati 2020) Peron adalah tempat yang digunakan untuk naik turun penumpang, peron harus memenuhi persyaratan teknis dan persyaratan operasi peron. Pada persyaratan peron digunakan hanya untuk naik turunnya penumpang dan harus memiliki batas aman peron.

Menurut Peraturan Menteri Nomor 29 tahun 2011 letak peron terbagi menjadi dua jenis yakni:

a) Peron sisi atau Side platform Peron sisi yaitu peron yang berada pada sisi kanan atau kiri rel. Biasanya peron ini terletak di tepi rel.

b) Peron Pulai atau Island Platform Peon pulau merupakan peron yang diapit oleh dua rel atau lebih di sisi yang berlainan.

Ada beberapa standar keselamatan yang harus dipenuhi dalam merencanakan peron. Menurut Peraturan Menteri Perhubungan Nomor 24 Tahun 2015 tentang Standar Keselamatan Perkeretaaapian pasal 9 ayat 8 menyatakan bahwa peron stasiun harus memenuhi persyaratan:

a) Ruang bebas dan ruang bangun

b) Permukaan lantai peron harus memiliki tahanan slip (slip resistance untuk kondisi basah dan kondisi kering dengan nilai pendulum slip tes lebih besar dari 30

c) Diberi garis batas aman sekurang-kurangnya $195 \mathrm{~cm}$ dari as jalan rel dengan garis yang terang.

d) Khusus untuk peron tinggi jarak antara (gap) tepi peron ke badan kereta maksimal $10 \mathrm{~cm}$ untuk lurusan dan $15 \mathrm{~cm}$ untuk lengkung: dan

e) Konstruksi penghubung antar peron yang sebidang dengan jalan rel harus dibuat dengan konstruksi perkerasan aspal atau beton dengan lebar $2 \mathrm{~m}$

Persyaratan diatas dapat mmenjamin keselamatan dan kenyamanan penumpang dalam menggunakan kereta api sebagai alat transportasi. Serta sebagai salah satu cara untuk memperbaiki sarana perkeretaapian guna peningkatan pelayanan perkeretaapian.

\section{METODE}

Alur pikir awal dalam rencana penelitian dengan melakukan pengumpulan data tentang peron eksisting baik data sekunder maupun data primer. Maka dari itu langkah pertama yang dilakukan adalah mencari informasi dasar yang telah diketahui dimana untuk informasi dasar tersebut didapatkan dari data sekunder setelah mendapatkan data sekunder maka diperlukan data primer untuk mendukung data sekunder yang telah didapat dimana untuk data primer dapat dilakukan dengan mencari tahu kondisi yang sebenarnya. Dari data primer yaitu dapat dilakukan dengan mencari kondisi sebenarnya seperti melakukan wawancara dengan narasumber yang terkait mengenai kondisi eksisting peron di Stasiun Tarik, pengoperasian kereta api di Stasiun Tarik dan peak our pada stasiun Tarik. Kemudian dari data tersebut selanjutnya dilakukan analisis permasalahan untuk membandingkan dengan data sekunder yang telah didapat, sehingga dapat diketahui permasalahan yang ada dan dicari penyelesaian dari permasalahan tersebut.

\section{PEMBAHASAN}

\section{Analisis Kondisi dan Level of Service Peron Eksisting}

a) Analisis Kondisi Peron Eksisting

Stasiun Tarik merupakan stasiun kelas sedang yang berada di wilayah kerja Balai Teknik Perkeretaapian Wilayah I Jawa Bagian Timur, stasiun ini berada di Kabupaten Sidoarjo, Provinsi Jawa Timur. Stasiun ini terletak pada KM 47+650 lintas Wonokromo-Tarik-Mojokerto. Ketersediaan fasilitas pelayanan penumpang pada stasiun merupakan salah satu upaya untuk memberikan keamanan, kenyamanan, kepuasan, kelancaran dan keamanan bagi pengguna jasa kereta api. Salah satu fasilitas pelayanan penumpang di stasiun yang sangat penting adalah peron. Peron berfungsi sebagai tempat yang digunakan untuk naik dan turun penumpang kereta api. Guna untuk mengetahui 
kondisi eksisting dari peron di stasiun Tarik maka dilakukan survei peron eksisting. Dari hasil survei dapat dilihat pada tabel V.1 berikut:

Tabel 1. Suveri Kondisi Peron Eksisting

\begin{tabular}{|c|c|c|c|c|}
\hline No & Aspek & Peron 1 & Peron 2 & Peron 3 \\
\hline 1 & Letak Peron & $\begin{array}{c}\text { Antara Bangunan Stasiun } \\
\text { dan Jalur 1 }\end{array}$ & $\begin{array}{c}\text { Antara Jalur 1 dan } \\
\text { Jalur 2 }\end{array}$ & $\begin{array}{c}\text { Antara Jalur 4 dan } \\
\text { Jalur 5 }\end{array}$ \\
\hline 2 & Jenis Peron & Peron Rendah & Peron Sedang & Peron Tinggi \\
\hline 3 & Panjang Peron & 30 Meter & 160 Meter & 10 Meter \\
\hline 4 & Lebar Peron & $200 \mathrm{~cm}$ & $540 \mathrm{~cm}$ & $270 \mathrm{~cm}$ \\
\hline 5 & Penempatan Peron & side platform & island platform & island platform \\
\hline 6 & Terdapat Lampu Pada Peron & Tidak Ada & Tidak Ada & Tidak Ada \\
\hline 7 & Terdapat Papan Petunjuk Jalur & Tidak Ada & Tidak Ada & Tidak Ada \\
\hline 8 & Terdapat Papan Petunjuk Arah & Tidak Ada & Tidak Ada & Tidak Ada \\
\hline 9 & Terdapat Batas Aman Peron & Ada & Ada & Ada \\
\hline 10 & Terdapat Kanopi & Tidak Ada & Tidak Ada & Ada \\
\hline 11 & Lantai Tidak Menggunakan & Sesuai & Sesuai & Tidak Sesuai \\
\hline
\end{tabular}

b) Analisis Level of Service Peron Eksisting

Dengan mengetahui luas peron dan panjang peron maka dapat diketahui tingkat pelayanan pada peron dengan menggunakan Level of Service.Hal ini dengan memperhitungkan jumlah penumpang pada saat jam sibuk. Dibawah ini merupakan hasil survei jumlah penumpang pada saat jam sibuk:

Tabel 2. Jumlah rata-rata penumpang pada saat jam sibuk

\begin{tabular}{|c|c|c|c|c|}
\hline No & Durasi Waktu & Senin & Sabtu & Minggu \\
\hline 1 & $06.00-07.00$ & 42 & 22 & 20 \\
\hline 2 & $07.00-08.00$ & 3 & 5 & 3 \\
\hline 3 & $08.00-09.00$ & 24 & 37 & 21 \\
\hline 4 & $09.00-10.00$ & 17 & 15 & 12 \\
\hline 5 & $10.00-11.00$ & 34 & 28 & 27 \\
\hline 6 & $11.00-12.00$ & 4 & 3 & 5 \\
\hline 7 & $12.00-13.00$ & 13 & 11 & 15 \\
\hline 8 & $13.00-14.00$ & 15 & 13 & 10 \\
\hline 9 & $14.00-15.00$ & 11 & 45 & 55 \\
\hline \multicolumn{2}{|}{ Jumlah } & 163 & 179 & 168 \\
\cline { 2 - 5 } & Jam Sibuk & 510 & \\
\hline \multicolumn{2}{|l}{} \\
\cline { 2 - 5 }
\end{tabular}

Dari tabel 2 digunakan untuk melakukan perhitungan Level of Service dengan mencari jumlah penumpang pada jam sibuk. Rata-rata penupang pada jam sibuk diambil dari hari tersibuk dalam satu minggu. Selain itu juga diambil jam tersibuk dalam satu hari. Berdasarkan survei yang dilakukan hari tersibuk pada Stasiun Tarik adalah Senin, Sabtu dan Minggu. Dan jam tersibuk dalam satu hari di Stasiun Tarik dimulai dari jam 6 pagi sampai dengan jam 3 sore. Rata-rata jumpah penumpang pada jam sibuk diperoleh dari penjumlahan penumpang pada tiga hari tersibuk dibagi jumlah hari tersibuk. Maka diperoleh hasil, jumlah penumpang Stasiun Tarik pada jam sibuk adalah 170 penumpang.

Dengan mengetahui lebar dan panjang peron eksisting maka dapat diketahui luas setiap peron eksisting. Hal ini berguna untuk mengetahui berapa Level of Servicepada setiap peron eksisting. Maka Level of Service pada setiap peron eksisting stasiun Tarik adalah sebagai berikut:

Tabel 3. Hasil Analisis Level of Service Pada Peron Eksisting Stasiun Tarik

\begin{tabular}{|c|c|c|c|c|}
\hline Peron & Panjang (m) & Lebar $(\mathbf{m})$ & Luas (m) & LOS (m $\left.\mathbf{m}^{2} \mathbf{p n p}\right)$ \\
\hline Peron 1 & 30 & 2 & 60 & $0,3(\mathbf{L O S ~ F})$ \\
\hline Peron 2 & 160 & 5,4 & 864 & $5(\mathbf{L O S ~ A )}$ \\
\hline Peron 3 & 108 & 2,7 & 291 & $1,7(\mathbf{L O S ~ C )}$ \\
\hline
\end{tabular}

Dari hasil perhitungan Level of Servicepada setiap peron menunjukkan tingkat kualitas pelayanan yang berbeda-beda. Peron 1 memiliki LOS F dengan pengertian semua penumpang antri 
dalam keadaan berdiri sehingga terjadi kontak fisik secara langsung antar orang. Kerapatan dirasakan tidak nyaman, tidak ada pergerakan dalam antrian. Peron 2 memiliki LOS A hal ini menunjukkan penumpang antri dengan berdiri tanpa ada gangguan satu sama lain, sirkulasi arus penumpang bebas tanpa ada gangguan. Peron 3 memiliki LOS C hal ini menunjukkan bahwa penumpang antri dalam keadaan berdiri dan ada pembatasan sirkulasi sehingga memungkinkan adanya gangguan antrian antar penumpang, tetapi masih ada faktor kenyamanan.

\section{Analisis Peramalan Jumlah Penumpang}

Peramalan atau yang disebut dengan forecasting adalah suatu teknik analisa perhitungan yang dilakukan dengan metode pendekatan secara kuantitatif ataupun kualitatif untuk melakukan perkiraan data pada masa depan dengan menggunakan referensi data-data pada tahun sebelumnya. Peramalan terhadap jumlah penumpang pada angkutan kereta api di Stasiun Tarik dilakukan untuk mendapat tingkat pertumbuhan penumpang tahun 2021 sampai dengan tahun 2025. Dalam melakukan perhitungan digunakan data jumlah penumpang dari tahun 2016 sampai dengan tahun 2020. Dalam mengitung peramalan tingkat pertumbuhan penumpang pada masa yang akan datang dihitung dengan menggunakan dasar jumlah penumpang pada tahun sebelumnya.

Tabel 4. Volume penumpang di Stasiun Tarik pada tahun 2016-2020

\begin{tabular}{|c|c|c|c|}
\hline \multirow{2}{*}{ Tahun } & \multirow{2}{*}{ Jumlah Penumpang } & \multicolumn{2}{|c|}{ Pertumbuhan Penumpang } \\
\cline { 3 - 4 } & & Penumpang & Presentase \\
\hline 2016 & 76.440 & - & - \\
\hline 2017 & 79.656 & 3.216 & $4 \%$ \\
\hline 2018 & 88.145 & 8.489 & $11 \%$ \\
\hline 2019 & 92.621 & 4.476 & $5 \%$ \\
\hline 2020 & 58.104 & -34.517 & $-37 \%$ \\
\hline Jumlah & 394.966 & -18.336 & $-17 \%$ \\
\hline
\end{tabular}

Dengan menggunakan data jumlah penumpang dari tahun 2016-2020 diatas makan diketahui pertumbuhan rata-rata penumpang per tahun pada Stasiun Tarik. Akan tetapi data yang diambil merupakan data penumpang tahun 2016-2020, dengan catatan pada tahun 2020 terjadi pandemi sehingga mengakibatkan penurunan pada jumlah penumpang yang sangat drastic akibat pandemic Covid-19 dan Pembatasan Sosial Berskala Besar (PSBB) yang berdampak pada peniadaan seluruh perjalanan kereta api.

Tabel 5. Volume penumpang di Stasiun Tarik pada tahun 2016-2020 Setelah Tahun 2020 disesuaikan dengan PM 18 Tahun 2020

\begin{tabular}{|c|c|c|c|}
\hline \multirow{2}{*}{ Tahun } & \multirow{2}{*}{ Jumlah Penumpang } & \multicolumn{2}{|c|}{ Pertumbuhan Penumpang } \\
\cline { 3 - 4 } & & Penumpang & Presentase \\
\hline 2016 & 76.440 & - & - \\
\hline 2017 & 79.656 & 3.216 & $4 \%$ \\
\hline 2018 & 88.145 & 8.489 & $11 \%$ \\
\hline 2019 & 92.621 & 4.476 & $5 \%$ \\
\hline 2020 & 116.208 & 23.587 & $25 \%$ \\
\hline Jumlah & 453.070 & 39.768 & $45 \%$ \\
\hline
\end{tabular}

Data yang diambil merupakan data penumpang tahun 2016-2020, dengan catatan pada tahun 2020 sedang terjadi pandemi sehingga mengakibatkan adanya pembatasan jumlah penumpang pada saat perjalanan. Berdasarkan Peraturan Menteri Nomor 18 Tahun 2020 yang menjelaskan adanya pembatasan jumlah penumpang paling banyak 50\% (lima puluh persen) dari jumlah tempat duduk dan penerapan jaga jarak fisik sesuai dengan konfigurasi tempat duduk. Sehingga untuk meramalkan jumlah penumpang pada kedepannya pada tahun 2020 jumlah penumpang yang dikalikan dua dengan asumsi jika tidak terjadi pandemi kemungkinan besar jumlah penumpang pada tahun 2020 akan mengalami peningkatan menjadi $100 \%$.

Pada perencanaan pembangunan prasarana khususnya peron jumlah penumpang menjadi salah satu dasar perencanaan tersebut. Proyeksi penumpang sangat bermanfaat dan merupakan kunci 
aktivitas perencanaan peron, Selain dapat dijadikan langkah dalam menentukan suatu arah dan dasar pengambilan keputusan rencana dimasa yang akan datang, juga dapat digunakan sebagai evaluasi pencapaian kegiatan pembangunan baik jangka pendek, jangka menengah, maupun jangka panjang. Karena Peron merupakan proyek jangka panjang maka data jumlah penumpang yang digunakan adalah data jumlah penumpang pada tahun 2020 yang sudah dikalikan 2. Proyeksi jumlah penumpang menggunakan data tahun sebelumnya tanpa adanya dampak pandemi. Hal ini untuk mengantisipasi kegiatan operasional kereta api setelah terjadi pandemi agar peron tetap dapat menampung penumpang pada masa yang akan datang pada saat keadaan sudah kembali normal. Proyeksi penumpang adalah suatu perkiraan jumlah penumpang dimasa yang akan datang. Untuk menentukan pilihan rumus proyeksi jumlah penumpang yang akan digunakan dengan hasil perhitungan yang paling mendekati kebenaran dan dilakukan analisis dengan cara menghitung standar deviasi dan memilih metode yang tepat untuk menghitung proyeksi jumlah penumpang 5 tahun mendatang.

Tabel 6. Hasil Perhitungan Metode Aritmatika, Least Squaredan Geometri

\begin{tabular}{|c|c|c|c|c|}
\hline \multirow{2}{*}{ Tahun } & Jumlah Penumpang & \multicolumn{3}{|c|}{ Hasil Perhitungan } \\
\cline { 2 - 5 } & Per Tahun & Aritmatic & Least Square & Geometric \\
\hline 2016 & 76.440 & $\mathbf{7 6 4 4 0}$ & 99864,1 & 76440 \\
\hline 2017 & 79.656 & $\mathbf{8 9 5 9 8}$ & 109114,2 & 94.888 \\
\hline 2018 & 88.145 & $\mathbf{1 0 8 0 2 9}$ & 118364,3 & 125.079 \\
\hline 2019 & 92.621 & $\mathbf{1 2 2 4 4 7}$ & 127614,4 & 156.563 \\
\hline 2020 & 116.208 & $\mathbf{1 5 5 9 7 6}$ & 136864,5 & 233.996 \\
\hline Jumlah & 453.070 & $\mathbf{5 5 2 4 9 0}$ & 591.882 & 686.966 \\
\hline \multicolumn{2}{r|}{} & $\mathbf{0 9 6 2 4 0 0 3 7}$ & 0,94503403 & 0,869391246 \\
\hline & $\mathrm{R}^{2}$ & $\mathbf{0 , 9 8 1 0 2 0 0 6}$ & 0,97213 & 0,93241 \\
\hline \multicolumn{2}{|r|}{} & $\mathbf{3 9 . 7 6 8}$ & 55.500 & 93.558 \\
\hline
\end{tabular}

Dengan adanya nilai korelasi (r) dan nilai standar deviasi (SD) dari ketiga metode diatas, metode proyeksi yang dipilih adalah metode proyeksi dengan nilai standar deviasi paling rendah dan koefisien korelasi paling besar. Oleh karena itu metode yang dipilih adalah metode Aritmatika. Berikut merupakan hasil analisis peramalan jumlah penumpang pada tahun 2021-2025.

Tabel 7. Hasil Perhitungan Peramalan Jumlah Penumpang pada Tahun 2021-2025

\begin{tabular}{|c|c|c|c|c|}
\hline No & Tahun & $\begin{array}{c}\text { Jumlah Penumpang per } \\
\text { Tahun }\end{array}$ & $\begin{array}{c}\text { Jumlah Penumpang Rata- } \\
\text { Rata per Hari }\end{array}$ & Keterangan \\
\hline 1 & 2016 & 76.440 & 209 & Data Sekunder \\
\hline 2 & 2017 & 79.656 & 218 & Data Sekunder \\
\hline 3 & 2018 & 88.145 & 241 & Data Sekunder \\
\hline 4 & 2019 & 92.621 & 254 & Data Sekunder \\
\hline 5 & 2020 & 116.208 & 318 & Data Sekunder \\
\hline 6 & 2021 & 165.918 & 461 & Hasil Prediksi \\
\hline 7 & 2022 & 175.860 & 489 & Hasil Prediksi \\
\hline 8 & 2023 & 185.802 & 517 & Hasil Prediksi \\
\hline 9 & 2024 & 195.744 & 544 & Hasil Prediksi \\
\hline 10 & 2025 & 205.686 & 572 & \\
\hline
\end{tabular}

Dari tabel peramalan penumpang tersebut, dapat diketahui bahwa volume penumpang semakin bertambah setiap tahunnya. Berdasarkan hasil perhitungan peramalan diatas diketahui pertumbuhan penumpang pada Stasiun Tarik akan terus bertambah hingga tahun 2025 dapat mencapai 205.686 penumpang.

\section{Perencanaan Peron Stasiun}

a) Panjang Peron

Dalam perencanaan peron pada stasiun Tarik diperlukan tersedianya panjang peron yang memadai. Melihat fungsi peron, maka diperlukan perencanaan panjang peron untuk tiap-tiap peron. Berdasarkan Peraturan menteri Perhubungan Nomor 29 Tahun 2011, panjang peron disesuaikan dengan rangkaian terpanjang kereta api penumpang yang beroperasi. 
Sarana yang berhenti di Stasiun Tarik adalah Kereta Dhoho, Kereta Jenggala dan Kereta Ekonomi Lokal Surabaya-Kertosono. Berikut merupakan analisis perhitungan panjang peron berdasarkan panjang kereta:

Tabel 8. Hasil Perhitungan Panjang Peron

\begin{tabular}{|c|c|c|c|c|}
\hline Nama KA & Panjang LOK & Panjang Kereta & Stanfo RMASI & Panjang Rangkaian \\
\hline Dhoho & 15,21 & 20,92 meter & 6K3ACS & $15,21+(20,92 \mathrm{~m} \times 6)=140,7 \mathrm{~m}$ \\
\hline Jenggala & - & 20 meter & 4 KDI3AC & $20 \mathrm{~m} \times 4=80 \mathrm{~m}$ \\
\hline Ekonomi Lokal & 14,13 & $20,92 \mathrm{~meter}$ & $6 \mathrm{~K} 3 \mathrm{ACS}$ & $14,13+(20,92 \mathrm{~m} \times 6)=139,6 \mathrm{~m}$ \\
\hline
\end{tabular}

b) Lebar Peron

Dalam perencanaan peron untuk menganalisis lebar peron menggunakan rangkaian kereta terpanjang yaitu kereta dhoho dan kereta Ekonomi Lokal dengan panjang yaitu $132 \mathrm{~m}$. Jumlah penumpang juga sangat berpengaruh dalam perhitungan lebar peron. Perhitungan lebar peron berdasarkan hasil perhitungan peramalan jumlah penumpang pada tahun 2025 diperkirakan rata-rata jumlah penumpang harian pada stasiun Tarik sebesar 572 .

Berdasarkan perhitungan lebar peron melalui banyaknya jumlah perkiraan pertumbuhan (forecasting) rata-rata penumpang per jam tahun 2025 di Stasiun Tarik maka dibutuhkan lebar peron dengan tipe di tepi jalur (side platform) yaitu peron 1 sebesar 2 meter dan untuk lebar peron dengan tipe diantara jalur (island platform) yaitu 4 meter.

c) Jenis Peron

Melihat kondisi peron di stasiun Tarik masih menggunakan peron rendah dan peron sedang sehingga naik turun penumpang kurang lancar, kurang aman dan serta membahayakan keselamatan penumpang terutama penumpang berkebutuhan khusus. Menurut Undang - Undang Nomor 8 Tahun 1999 tentang Perlindungan Konsumen yaitu hak atas kenyamanan, keamanan dan keselamatan dalam mengkonsumsi barang dan/atau jasa maka penumpang berhak memperoleh kenyamanan dalam pelayanan dalam menjamin keselamatan menggunakan jasa kereta api (Syamsudin 2011). Berdasarkan Peraturan Menteri Perhubungan Nomor 29 tahun 2011 tentang Persyaratan Teknis Bangunan Stasiun Kereta Api Peron peron perlu ditinggikan sesuai dengan desain, ukuran dan kapasitas bangunan yang sesuai dengan standart kelayakan keselamatan dan keamanan.

Perubahan desain emplasemen berakibat berubahnya desain dan tata letak peron, Peron yang merupakan peron rendah dan sedang perlu diganti dengan peron tinggi. Tinggi peron dibangun sesuai dengan Peraturan Menteri No 29 Tahun 2011 tentang Persyaratan Teknis Bangunan Stasiun dengan ketentuan sebagai berikut:

1) Peron tinggi, tinggi peron $1000 \mathrm{~mm}$, diukur dari kepala rei;

2) Peron sedang, tinggi peron $430 \mathrm{~mm}$, diukur dari kepala rei; dan

3) Peron rendah, tinggi peron $180 \mathrm{~mm}$, diukur dari kepala reI.

Hal ini sejalan dengan rencana pengembangan stasiun untuk proyek jalur ganda lintas Sepanjang-Mojokerto, Balai Teknik Perkeretaapian Wilayah I Jawa Bagian Timur menyebutkan bahwa stasiun Tarik akan mengalami peningkatan peron menjadi peron tinggi. Maka sesuai dengan Peraturan Menteri No 29 Tahun 2011 peron tinggi pada stasiun Tarik dibangun dengan tinggi peron $1000 \mathrm{~mm}$ diukur dari kepala rel.

\section{Analisis Pergerakan Penumpang}

Pergerakan perjalanan penumpang merupakan salah satu hal yang perlu diketahui untuk merencanakan pembangunan peron. Peron yang berfungsi sebagai tempat yang digunakan untuk aktivitas naik dan turun penumpang kereta api, memerlukan perencanaan yang cukup matang. Stasiun Tarik mengalami perubahan penempatan peron yang dikarenakan perubahan emplasemen stasiun akibat pembangunan jalur ganda. Dengan memperkirakan pertumbuhan jumlah penumpang pada masa yang akan datang diperlukan kemudahan untuk keluar dan masuk stasun. Mobilitas penumpang 
ini menjadi salah satu pertimbangan dalam merencanakan peron yang memberikan rasa aman dan nyaman.

Berdasarkan hasil observasi, diketahui pintu keluar tidak difungsikan sehingga arus pergerakan masuk dan keluar penumpang di Stasiun tarik hanya tersedia satu jalur melalui pintu masuk. Sehingga mengakibatkan penumpang terutama pada saat jam sibuk terjadi penumpukan terutama di pintu masuk.

Melihat kondisi tersebut alur pergerakan penumpang memerlukan perencanaan yang baik dengan didukung kemudahan dalam akses keluar masuk stasiun apabila terjadi penumpukan penumpang pada waktu jam sibuk. Selain itu juga mempertimbangkan kegiatan-kegiatan di stasiun meliputi proses naik dan turun dari kereta api, proses pembelian dan pemeriksaan tiket kereta api. Akses pintu masuk dan keluar stasiun dari peron atau menuju peron perlu dipisahkan.

Kemudian berdasarkan rancangan denah stasiun Tarik untuk pembangunan jalur ganda, sebaiknya arus pergerakan penumpang difasilitasi dengan pintu keluar yang berbeda dengan pintu masuk. Untuk melancarkan pergerakan penumpang menuju dan meninggalkan peron maka dilakukan perencanan dengan membuat akses keluar baru yang berada di samping kanan stasiun. Hal ini akan mengakibatkan terjadinya pemisahan arus penumpang yang akan menuju peron dan penumpang yang akan meninggalkan peron sehingga kondisi ini memberikan kemudahan kepada penumpang dalam beraktivitas naik dan turun kereta api. Dengan pemisahan pintu masuk dan keluar maka pergerakan alur penumpang lebih efektif dan efisien dalam melakukan kegiatan di stasiun. Pemisahan pintu masuk dan keluar ini dapat mengurai penumpukan di stasiun sehingga memperkecil terjadinya konflik point.

\section{KESIMPULAN}

Berdasarkan hasil analisis dan pembahasan yang telah dilakukan maka dapat diambil kesimpulan sebagai bahwa kondisi dan Level of Servicepada setiap peron eksisting di Stasiun Tarik, terdapat peron yang tidak sesuai dengan peraturan Menteri Perhubungan Nomor 29 Tahun 2011 tentang Persyaratan Teknis Bangunan Stasiun Kereta Api. Peron 1 masih terdapat masalah terkait panjang peron yang tidak sesuai dengan rangkaian kereta terpanjang yang berhenti pada stasiun Tarik, dengan panjang peron eksisting 30 meter seharusnya panjang peron minimal 140,7 meter. Peron 2 sudah sesuai persyaratan teknis pembangunan peron. Peron 3 yang terletak diantara dua jalur (island platform) seharusnya mempunyai panjang minimal 4 meter dan panjang peron eksisting 108 meter seharusnya panjang peron minimal 140,7 meter. Kemudian Sesuai dengan perhitungan peramalan jumlah penumpang pada tahun 2025 sebesar 205.686 per tahun. Karena bertambahnya jumlah penumpang di Stasiun Tarik dan adanya pembangunan jalur ganda lintas Sepanjang-Mojokerto lebar peron sebesar 2 meter untuk peron yang terletak di tepi jalur dan 4 meter untuk peron yang terletak diantara dua jalur. Sedangkan untuk panjang peron sebesar 140,7 meter, maka perlu adanya peningkatan peron dengan menambah luas dan tinggi peron serta meningkatkan perlengkapan peron. Terakhir Pada denah eksisting Stasiun Tarik masih mengalami kekurangan karena pintu keluar tidak difungsikan sehingga arus pergerakan masuk dan keluar penumpang di Stasiun tarik hanya tersedia satu jalur melalui pintu masuk. Sehingga mengakibatkan penumpang terutama pada saat jam sibuk terjadi penumpukan terutama di pintu masuk.

\section{REFERENSI}

1. M. H. Aswad. (2018). "Analisis Peramalan Jumlah Penduduk Kota Palopo Tahun 2013 - 2017." Al-Khwarizmi: Jurnal Pendidikan Matematika Dan Ilmu Pengetahuan Alam 1 (August): 49-58. https://doi.org/10.24256/jpmipa.v1i1.83.

2. Handinoto. (1999). "Perletakan Stasiun Kereta Api Dalam Tata Ruang Kota-Kota Di Jawa (Khususnya Jawa Timur) Pada Masa Kolonial.” DIMENSI (Jurnal Teknik Arsitektur) 27 (2): 4856. http://puslit2.petra.ac.id/ejournal/index.php/ars/article/view/15717.

3. H. F. Rohman. (2016). Metode Least Square Untuk Prediksi Penjualan Sari Kedelai Rosi. Simetris: Jurnal Teknik Mesin, Elektro Dan Ilmu Komputer 7(2): 731. https://doi.org/10.24176/simet.v7i2.788. 
4. H. I. R. Sitepu., \& N. Tamba. (2019). Metode Geometri, Metode Aritmatika, Dan Metode Eksponensial Untuk Memproyeksikan Penduduk Provinsi Sumatera Selatan. Prosiding Seminar Nasional Sains Matematika Informatika Dan Aplikasinya IV4(4): 7-18.

5. Kementerian Perhubungan. 2011a. "PM 33 Tahun 2011 Tentang Jenis, Kelas Dan Kegiatan Di Stasiun Kereta Api." Jaringan Dokumentasi Dan Informasi Hukum Kementrian Perhubungan1999.

6. Kementerian Perhubungan. 2011b. "PM Nomor 29 Tahun 2011 Tentang Persyaratan Teknis Bangunan Stasiun Kereta Api.” Kementerian Perhubungan, 1-13. https://djka.dephub.go.id/uploads/201908/pm._no._29_tahun_2011.pdf.

7. Kementerian Perhubungan. 2015. "PM 24 Tahun 2015 Tentang Standart Keselamatan Perkeretaapian."

8. Kementerian Perhubungan. 2019. "PM 63 Tahun 2019 Standar Pelayanan Minimum Angkutan Orang Dengan Kereta Api.” Jakarta, no. 3: 13.

9. Kementerian Perhubungan. 2020. "PM 18 Tahun 2020 Tentang Pengendalian Transportasi Dalam Rangka Pencegahan Penyebaran Corona Viru Disease 2019 (COVID 19)."

10. Khamdevi, Muhammar. 2015. "Pengaruh Setting Peron Terhadap Adaptabilitas Pengguna Krl Studi Kasus: Stasiun Kereta Api Kebayoran Pada Jam Sibuk." JurnalNalars. https://jurnal.umj.ac.id/index.php/nalars/article/view/174/155.

11. Kittelson \& Associates, KFH Group, Parsons Brinckerhoff Quade \& Douglass, and Katherine Hunter-Zaworski. 2003. Transit Capacity and Quality of Service Manual (TCRP Report 100). TCRP Report.

12. L. Anna., \& P. Yuliarty. (2020). "Penerapan Metode Peramalan (Forecasting) Pada Permintaan Atap Di PT X.” Industri Inovatif: Jurnal Teknik Industri, 10(1): 11-20. https://doi.org/10.36040/industri.v10i1.2530.

13. Maulana, Algifakhri Bagus. 2019. "Perencanaan Stasiun Kereta Api Pontianak Di Kecamatan Ambawang Dengan Pendekatan Perancangan Santiago Calatrava" 6: 55-68.

14. Mony, Rizky Farezi, I Made Suraharta, Politeknik Transportasi, and Darat Indonesia. 2020. "Pengembanan Fasilitas Dan Utilitas Stasiun Bumiayu Guna Meningkatkan Pelayanan Terhadap Penumpang" 4 (November).

15. Mufassirin, Ibnu, Budi Arief, and Puji Wiranto. 2020. "Kajian Analisis Kinerja Stasiun Kereta Api (Studi Kasus : Stasiun Kereta Api Tipe A Bogor )," 1-16.

16. Muthohar, Imam, Aisyah Nurjannah, Universitas Gadjah Mada, and Kereta Api. 2018. "Implikasi Peningkatan Emplasemen Stasiun KA Dan Fasilitas Pendukungnya Terhadap Rantai Distribusi Semen Di Koridor Selatan Jawa ( Studi Kasus : Emplasemen Stasiun KA Kebumen )" 2018 (November): 310- 17.

17. Nurdiansyah, M Alfian, and Sudarwati. 2020. "Perencanaan Peningkatan Emplasemen Stasiun Sukabumi Untuk Mendukung Operasional Jalur Ganda Bogor-Sukabumi.” Jurnal Teknik SipillArsitektur19 (1): 49-56.

18. Priyambodo. 2015. "Analisis Aksesibilitas Dan Level Of Service Angkutan Jalan Lintas Surabaya - Kediri." Warta Penelitian Perhubungan $27 \quad$ (2): 129. https://doi.org/10.25104/warlit.v27i2.779.

19. Republik Indonesia. 2007. "UU RI No. 23 Tahun 2007 Tentang Perkeretaapian,” no. 1: 634.

20. Republik Indonesia. 2020. "Perpres No. 109 Tahun 2020 Tentang Perubahan Ketiga Atas Perpers No. 3 Tahun 2016 Tentang Percepatan Pelaksanaan Proyek Strategis Nasional” 9 (050197): 144.

21. Rizki, Teshanda, Adi Sasmito, and Margareta Maria. 2015. "Perancangan Stasiun Kereta Api Terpadu Dengan Terminal Bus Di Semarang." Journal of Architecture1: 1-20.

22. Sidoarjo, BPS Kabupaten. 2021. "Sidoarjo Dalam Angka 2021," 283. Silaban, Andry Rizky, Slamet Widodo. 2017. "Analisis Kapasitas Terminal Penumpang Pelabuhan Dwikora Pontianak Di Kalimantan Barat," 1-9. 
23. Syamsudin, M. 2011. "Aspek Yuridis Pembangunan Peron Tinggi Di Stasiun Kereta Api Sebagai Sarana Perlindungan Hukum Konsumen," 345-52.

24. Taufiqqurokhman. 2008. Konsep Dan Kajian Ilmu Perencanaan. Jakarta: Fakultas Ilmu Sosial dan Ilmu Politik Universitas Prof. Dr. Moestopo Beragama.

25. Wiasanto, Alkahfian Ramadhani, Wahju Herijanto, and Budi Rahardjo. 2019. "Kajian Jalur Ganda Kereta Api Stasiun Blitar -Stasiun Kertosono Sta 122 +895 - 215 +479." Jurnal $\begin{array}{llllll}\text { Transportasi: } & \text { Sistem, } & \text { Material, Dan } & \text { Infrastruktur2 } & \text { (2): } & 78 .\end{array}$ https://doi.org/10.12962/j26226847.v2i2.5485. 